\title{
GriC and GriD Constitute a Carboxylic Acid Reductase Involved in Grixazone Biosynthesis in Streptomyces griseus
}

\author{
Hirokazu Suzuki, Yasuo Ohnishi, Sueharu Horinouchi
}

Received: May 11, 2007 / Accepted: June 5, 2007

(C) Japan Antibiotics Research Association

\begin{abstract}
In grixazone biosynthesis by Streptomyces griseus, a key intermediate 3-amino-4-hydroxybenzoic acid (3,4-AHBA) is converted to another key intermediate 3amino-4-hydroxybenzaldehyde (3,4-AHBAL). Two genes griC and griD in the grixazone biosynthesis gene cluster were found to be responsible for this conversion, because disruption of each gene resulted in the extracellular accumulation of 3-acetylamino-4-hydroxybenzoic acid, a shunt product from 3,4-AHBA. Significant sequence similarity of GriC to AMP-binding proteins and of GriD to NAD(P)-dependent aldehyde dehydrogenases suggested that GriC and GriD constituted an ATP- and NAD(P)dependent carboxylic acid reductase (CAR) catalyzing reduction of 3,4-AHBA to produce 3,4-AHBAL through acyl-AMP formation, as is found for the reactions catalyzed by some CARs. griG encoding a benzoate transporter homologue in the grixazone biosynthesis gene cluster was nonessential for grixazone biosynthesis but probably enhanced the membrane permeability for 3,4-AHBA. Simultaneous overexpression of griC, griD, and griG in $S$. griseus mutant cells deficient in an acetyltransferase responsible for $N$-acetylation of 3,4-AHBA led to efficient bioconversion of exogenously added 3,4-AHBA to 3,4AHBAL. This system also turned out to be useful for reduction of some aryl carboxylates to the corresponding aryl aldehydes.
\end{abstract}

Keywords Streptomyces griseus, grixazone, biosynthesis, carboxylic acid reductase, bioconversion, 3-amino-4hydroxybenzoic acid, benzoate transporter

S. Horinouchi (Corresponding author), H. Suzuki, Y. Ohnishi: Department of Biotechnology, Graduate School of Agriculture and Life Sciences, The University of Tokyo, Bunkyo-ku, Tokyo 113-8657, Japan, E-mail: asuhori@mail.ecc.u-tokyo.ac.jp.

\section{Introduction}

The filamentous, soil-inhabiting, Gram-positive bacterial genus Streptomyces is characterized by its ability to produce a wide variety of secondary metabolites including antibiotics and biologically active substances. We have studied the A-factor regulatory cascade that leads to secondary metabolite formation and morphological differentiation in Streptomyces griseus [1]. Grixazone, consisting of grixazone A (see Fig. 2 for its structure) and grixazone B (in which the aldehyde group of grixazone A is replaced by a carboxyl group) showing a parasiticide activity [2], is one of the secondary metabolites under the control of A-factor [3]. The grixazone biosynthesis gene cluster contains 13 genes [4], including gril-griH and griEgriF (Fig. 1A). griI and griH encode an aldolase and 3dehydroquinate synthase homologues, respectively. griEgriF are homologous to melC1-melC2 of streptomycetes, in which melC1 and melC2 encode a tyrosinase cofactor and a tyrosinase, respectively. We previously characterized these four genes and revealed two enzymatic reactions involved in grixazone biosynthesis (see Fig. 2), both of which had been unpredictable only on the basis of protein homology. One is the GriI-GriH reaction responsible for the formation of 3-amino-4-hydroxybenzoic acid (3,4-AHBA) from two primary metabolites, L-aspartate-4-semialdehyde and dihydroxyacetone phosphate [5]. The other is the GriE-GriF reaction responsible for the formation of the phenoxazinone chromophore of grixazones from two molecules of 3-amino-4-hydroxybenzaldehyde (3,4AHBAL) [6]. These findings predicted that an enzyme(s) catalyzing the reduction of 3,4-AHBA to produce 3,4AHBAL might be involved in grixazone biosynthesis and the enzyme gene(s) would be encoded in the gene cluster. 
In this study, we identified griC and griD responsible for reduction of 3,4-AHBA to produce 3,4-AHBAL. griC encodes an AMP-binding protein, and griD encodes a protein exhibiting sequence similarity to some aldehyde dehydrogenases. Although griC-griD homologues have been found in other gene clusters, including those for biosynthesis of phenazine antibiotic D-alanylgriseoluteic acid in Erwinia herbicola [7] and a $\beta$-lactam antibiotic carbapenem, thienamycin, in Streptomyces cattleya [8], their functions have not been elucidated. Here we report that GriC-GriD are essential for grixazone biosynthesis and constitute a carboxylic acid reductase that reduces 3,4-AHBA to 3,4-AHBAL. In addition to the GriCGriD function, we found that $g r i G$ encoding a benzoate transporter homologue in the grixazone biosynthesis gene cluster had an apparently important role for efficient import of exogenously added 3,4-AHBA, although it was nonessential for grixazone biosynthesis.

\section{Materials and Methods}

\section{Strains, Plasmids, Media, and Chemicals}

S. griseus IFO13350 was obtained from the Institute of Fermentation, Osaka, Japan. A natA null mutant ( $\Delta$ natA) of S. griseus was constructed previously [9]. S. griseus strains were grown at $30^{\circ} \mathrm{C}$ in YPD medium $(0.2 \%$ yeast extract, $0.4 \%$ Bacto peptone, $0.5 \% \mathrm{NaCl}, 0.2 \% \mathrm{MgSO}_{4} \cdot 7 \mathrm{H}_{2} \mathrm{O}$, $1.0 \%$ glucose, and $0.5 \%$ glycine, $\mathrm{pH} 7.2$ ) or at $26.5^{\circ} \mathrm{C}$ in standard minimal medium [SMM; $0.9 \%$ glucose, $0.9 \%$ asparagine, $0.2 \%\left(\mathrm{NH}_{4}\right)_{2} \mathrm{SO}_{4}, 0.24 \%$ Trizma base, $0.1 \%$ $\mathrm{NaCl}, 0.05 \% \mathrm{~K}_{2} \mathrm{SO}_{4}, 0.02 \% \mathrm{MgSO}_{4} \cdot 7 \mathrm{H}_{2} \mathrm{O}, 0.01 \% \mathrm{CaCl}_{2}$, $2.5 \mathrm{mM} \mathrm{KH}_{2} \mathrm{PO}_{4}$, and $1.0 \%$ trace element solution [10], $\mathrm{pH}$ 7.2]. For grixazone production, $S$. griseus cells were cultured for 5 days in $\mathrm{SMM}$, the $\mathrm{KH}_{2} \mathrm{PO}_{4}$ concentration of which was $0.25 \mathrm{mM}$ to allow expression of the grixazone biosynthesis genes [4]. We referred to the standard $(2.5 \mathrm{mM}$ $\left.\mathrm{KH}_{2} \mathrm{PO}_{4}\right)$ and low-phosphate $\left(0.25 \mathrm{mM} \mathrm{KH_{2 }} \mathrm{PO}_{4}\right) \mathrm{SMM}$ media as SMM-2.5 and SMM-0.25, respectively. SMM-2.5 was used for bioconversion experiments. A thiostrepton resistance plasmid pIJ702 containing the melC promoter [11], with its copy number of 40 to 300 [10], was used for DNA manipulation and gene expression in $S$. griseus. The melC promoter is active in the late exponential and stationary growth phases. Escherichia coli strains JM109, JM110, TOP10 (Invitrogen), and BL21 [pGro7] (Takara Biochemicals) and plasmids pUC19, pCR4Blunt-TOPO (Invitrogen), and pCold III (Takara Biochemicals) were used for DNA manipulation in E. coli. Restriction enzymes, T4 DNA ligase, Pyrobest DNA polymerase, and other DNA-modifying enzymes were purchased from
Takara Biochemicals. 3,4-AHBAL, 3-acetylamino-4hydroxybenzoic acid (3,4-AcAHBA), and 3-acetylamino4-hydroxybenzaldehyde (3,4-AcAHBAL) were prepared as described previously [5, 6]. Other chemicals were purchased from Wako Chemicals. The absence of undesired alterations during PCR was checked by nucleotide sequencing.

\section{Gene Disruption}

The chromosomal griC, griD, and griG genes of $S$. griseus IFO13350 were disrupted as follows (Fig. 1A). Correct disruption was checked by Southern hybridization (data not shown). A 1.1-kb fragment containing a $3^{\prime}$ portion of griC and its downstream region was amplified by PCR with primers, 5'-TGGGAATTCGTCTACTGATGAGCACCGTCGCAC-3' (with an EcoRI site shown by underlining and the stop codon of griC shown in italics) and 5'-CACGACGGTCTCCGGATCCCC-3' (with an inherent BamHI site shown by underlining). The amplified fragment was digested with EcoRI and BamHI, ligated with a $1.3-\mathrm{kb}$ Bam HI fragment containing a further downstream region from griC, and placed between the EcoRI and BamHI sites of pUC19. From the resulting plasmid, the 2.4-kb EcoRIHindIII fragment was excised and connected with a $3.4-\mathrm{kb}$ $B g l \mathrm{II}-E c o$ RI fragment containing a 5' portion of griC and
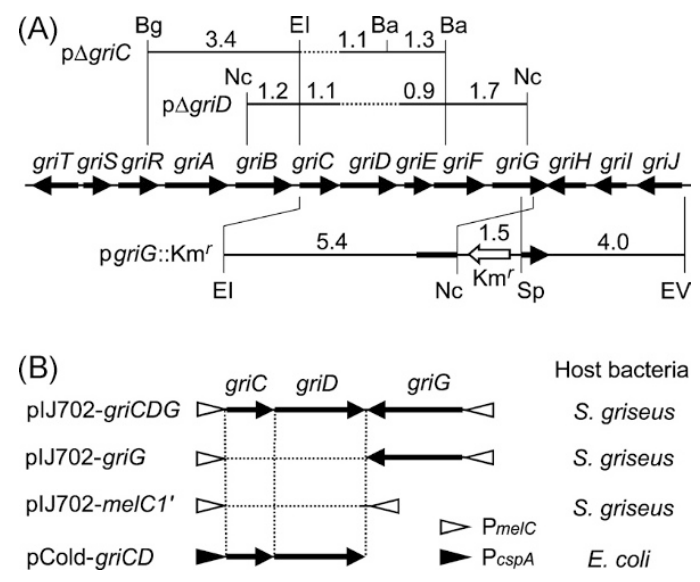

Fig. 1 Schematic representation of the DNA fragments on plasmids used in this study.

(A) Gene organization of the grixazone biosynthesis gene cluster [4] and DNA fragments on plasmids used for gene disruption. The restriction enzyme abbreviations: $\mathrm{Ba}, \mathrm{BamHI}, \mathrm{Bg}$, $\mathrm{Bglll}$; El, EcoRl; EV, EcoRV; Nc, Ncol; and Sp, Sphl. Kmr represents the kanamycin/neomycin resistance gene from Tn5. Numerals indicate the length of DNA fragments in $\mathrm{kb}$. The $\mathrm{Km}^{\mathrm{r}}$ cassette in $\mathrm{p} \Delta$ griC and $\mathrm{p} \Delta$ griD is not shown. (B) DNA fragments on plasmids used for gene expression in S. griseus [plJ702-griCDG, plJ702griG, and plJ702-melC1'] and in E. coli [pCold-griCD]. $P_{\text {melc }}$ the melC promoter; $\mathrm{P}_{\text {cspA }}$, the $\operatorname{csp} A$ promoter. 
its upstream region. This 5.8-kb fragment, which had a 1.0$\mathrm{kb}$ in-frame deletion in $\mathrm{griC}$ (from Asp-10 to Gly-350 of GriC), was placed between the BamHI and HindIII sites of pUC19, together with a 1.1-kb HindIII fragment carrying the kanamycin/neomycin resistance gene from $\mathrm{Tn} 5$, resulting in $\mathrm{p} \Delta$ griC. The plasmid was alkali-denatured and introduced by protoplast transformation into $S$. griseus IFO13350. Neomycin $(5 \mu \mathrm{g} / \mathrm{ml})$-resistant transformants containing $\mathrm{p} \Delta \mathrm{griC}$ in the chromosome, as a result of a single crossover, were first isolated, and one of the transformants was cultured several times on YPD medium without neomycin. A neomycin sensitive colony was isolated as the true $\mathrm{griC}$-disruptant (mutant $\Delta$ griC).

A $1.1-\mathrm{kb}$ fragment containing a $5^{\prime}$ portion of griD and its upstream region was amplified by PCR with primers, $5^{\prime}$ CGATGATCCCGAATTCGACAGTC-3' (with an inherent EcoRI site shown by underlining) and 5'-TGGTCTAGAGTGCGACGGTGCTCATCAGTAGAC-3' (with an XbaI site shown by underlining and the start codon of griD shown in italics). The amplified fragment was digested with EcoRI and $X b a \mathrm{I}$, and ligated with a $1.2-\mathrm{kb} N c o \mathrm{I}-E c o$ RI fragment containing a further upstream region from griD. This 2.3$\mathrm{kb} N c o \mathrm{I}-X b a \mathrm{I}$ fragment was placed between the HindIII and $X b a \mathrm{I}$ sites of pUC19 using a short linker composed of HindIII-SphI-PstI-SalI-XbaI-BamHI-SmaI-NcoI sites. From the resulting plasmid, a 2.3-kb $X b a$ I fragment was excised and used for further plasmid construction. On the other hand, a $0.9-\mathrm{kb}$ fragment containing a $3^{\prime}$ portion of griD and its downstream region was amplified by PCR with primers, 5'-TGGTCTAGACCCGGCGCTGACCCCTCCCG-3' (with an $X b a$ I site shown by underlining and the stop codon of griD shown in italics) and 5'-TCAGGGCCGGATCCTCGGGG-3' (with an inherent BamHI site shown by underlining). The amplified fragment was digested with $X b a \mathrm{I}$ and BamHI, and ligated with a 1.7-kb Bam HI-NcoI fragment containing a further downstream region from

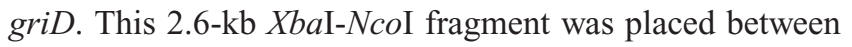
the $X b a \mathrm{I}$ and EcoRI sites of pUC19 using a short linker composed of NcoI-SmaI-KpnI-SacI-EcoRI sites. At the $X b a \mathrm{I}$ site of the resulting plasmid, the 2.3-kb $X b a \mathrm{I}$ fragment described above was placed in the correct orientation. This plasmid contained a deleted griD sequence, encoding a hexapeptide of the first 5 amino acids of GriD (Met-SerThr-Val-Ala) followed by Leu, with the 2.3-kb upstream and 2.6-kb downstream regions from griD. Finally, a $1.1-\mathrm{kb}$ HindIII fragment carrying the kanamycin/neomycin resistance gene from $\operatorname{Tn} 5$ was placed at the HindIII site of the plasmid, resulting in $\mathrm{p} \Delta$ griD. By use of this plasmid, a griD-disruptant (mutant $\Delta g r i D$ ) was similarly isolated by the method used for obtaining the $\mathrm{griC}$-disruptant.

A 5.4-kb EcoRI-NcoI fragment containing a $5^{\prime}$ portion of $\operatorname{gri} G$ and its upstream region was connected with a 1.5$\mathrm{kb}$ Sall-HindIII fragment carrying the kanamycin/neomycin resistance gene from $\mathrm{Tn} 5$, mediated by a short linker composed of NcoI-SmaI-KpnI-SmaI-BamHI-XbaI-SalI sites, to give a $6.9-\mathrm{kb} E c o$ RI-HindIII fragment. A $4.0-\mathrm{kb}$ $S p h$ I-EcoRV fragment containing a $3^{\prime}$ portion of griG and its downstream region was connected with an $S p h$ I linker and placed in the $S p h$ I site of pUC19. From the resulting plasmid, a 4.0-kb HindIII-PstI fragment was excised and placed between the EcoRI-PstI sites of pUC19, together with the 6.9-kb EcoRI-HindIII fragment described above, resulting in $\operatorname{pgri} G:: \mathrm{Km}^{\mathrm{r}}$. In this construct, griG was separated to two fragments that overlapped partially, from the $5^{\prime}$-terminus to position +1030 (corresponding to the $N c o$ I site) and from position +857 (corresponding to the $S p h$ I site) to the $3^{\prime}$-terminus, by the kanamycin/neomycin

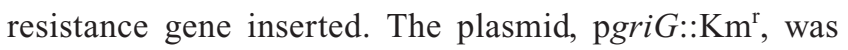
digested with $\operatorname{DraI}$, alkali-denatured, and introduced by protoplast transformation into $S$. griseus. A neomycinresistant transformant, as a result of double crossover between the disrupted griG sequence and the intact chromosomal griG sequence, was isolated as the true griGdisruptant (mutant $g r i G:: \mathrm{Km}^{\mathrm{r}}$ ).

\section{Construction of Plasmids}

A $0.5-\mathrm{kb}$ fragment containing the melC promoter and the 5 '-portion (173 bp) of melCl was amplified by PCR using pIJ702 as a template and primers, 5'-CTGCAGAAGCTTGAATTCTGATCACGTCAGTTTTC-3' (with a HindIII site and an EcoRI site shown by underlining) and 5'AAGCTTCTGCAGTTGTAGATCTCGTCGAAG-3' (with a Pst I site and an inherent BglII site shown by underlining). The amplified fragment, which contained an $S p h$ I site (GC $\underline{A T G C)}$ overlapping with the start codon of melC1 shown by underlining, was digested with HindIII plus PstI and cloned into pUC19, resulting in pUC702. This plasmid was used for the construction of expression plasmids in $S$. griseus, pIJ702-griG and pIJ702-griCDG.

The $0.5-\mathrm{kb} E c o$ RI-BglII fragment excised from pUC702 was placed between the $B g l I I$ and $E c o$ RI sites of a pIJ702derived plasmid, in which the melC1-melC2 sequence under the melC promoter was replaced by a short linker containing SphI, BglII, and EcoRI sites, resulting in pIJ702-melC1' (Fig. 1B). This plasmid was used as a negative control plasmid. The griG sequence was amplified by PCR using primers, 5'-CATGTACGCAGTACTCGCC$3^{\prime}$ (with the start codon of griG shown in italic) and 5'CTCGAGAGATCTTCAACGAGTTCTGCCTG-3' (with the stop codon of griG shown in italic and a BglII site shown by underlining). The amplified fragment was digested with $B g l I I$ and placed in pUC702, which had been digested with 
SphI, blunted with T4 DNA polymerase, and digested with $B g l$ II. From the resulting plasmid, a $1.7-\mathrm{kb} E c o$ RI-BglII fragment containing the griG sequence under the melC promoter was excised and placed between the EcoRI and $B g l$ II sites of the pIJ702-derived plasmid, resulting in pIJ702-griG (Fig. 1B).

The inherent co-translational griC-griD sequence was amplified by PCR using primers, 5'-GCATGCTCCTCATCGATGATC-3' (with the start codon of griC shown in italic and an SphI site shown by underlining) and 5'AGATCTTCAGCGCCGGGCCACGAC-3' (with the stop codon of griD shown in italic and a BglII site shown by underlining). After the amplified fragment had been cloned into pCR4Blunt-TOPO, the griC-griD sequence was excised with $S p h$ I plus $B g l I I$ and cloned into the pIJ702derived plasmid. Between the BglII and NdeI sites of the resulting plasmid, a $2.7-\mathrm{kb} B g l \mathrm{II}-\mathrm{NdeI}$ fragment containing the $g r i G$ sequence under the $m e l C$ promoter from $\mathrm{pIJ702-}$ griG were placed, resulting in pIJ702-griCDG (see Fig. 1B).

The griC-griD sequence was amplified by PCR using primers, 5'-GGAATTCCATATGAGCCTCATCGATG-3' (with the start codon of griC shown in italic and an NdeI site shown by underlining) and 5'-GCTCGAGTTAGCGCCGGGCCACGAC-3' (with the stop codon of griD shown in italic and an XhoI site shown by underlining). After the amplified fragment had been cloned into pCR4Blunt-TOPO, the griC-griD sequence was excised with NdeI plus XhoI and cloned into pCold III for expression in $E$. coli, resulting in pCold-griCD. On this plasmid, griC and griD were under the control of the $\operatorname{csp} A$ promoter that is inducible by cold-shock.

\section{Bioconversion Conditions}

S. griseus cells were precultured at $30^{\circ} \mathrm{C}$ for 2 days in $100 \mathrm{ml}$ of YPD liquid medium supplemented with $10 \mu \mathrm{g} / \mathrm{ml}$ thiostrepton. The mycelium (about $4 \mathrm{~g}$ wet weight) was harvested by centrifugation, washed twice, resuspended in $10 \mathrm{ml}$ of SMM-2.5, and homogenized. A portion $(100 \mu \mathrm{l})$ of the homogenized solution was inoculated to $100 \mathrm{ml}$ of fresh SMM-2.5 and cultured at $26.5^{\circ} \mathrm{C}$ for 2 days (up to the late exponential phase), and then an aryl carboxylic acid was added at a final concentration of $10 \mathrm{mM}$. After the cells were further incubated for $1 \sim 3$ days, compounds in the culture broth were analyzed by reversed-phase highperformance liquid chromatography (HPLC), as described previously [6]. The aryl aldehydes produced were determined by liquid chromatography-electrospray ionization mass spectrometry, as described previously [5], in reference to the authentic compounds available commercially. The amounts of the aryl aldehydes produced were determined by HPLC in reference to the authentic compounds.

The conditions for the conversion of 3,4-AHBA to 3,4AHBAL in E. coli were as follows. The cells of E. coli BL21 [pCold-griCD and pGro7] ([ ] denotes plasmidcarrier state) were incubated at $37^{\circ} \mathrm{C}$ to an optical density 0.6 at $600 \mathrm{~nm}$ in LB medium supplemented with $50 \mu \mathrm{g} / \mathrm{ml}$ ampicillin and $20 \mu \mathrm{g} / \mathrm{ml}$ chloramphenicol, and then placed in a water bath at $15^{\circ} \mathrm{C}$ for 30 minutes. Isopropyl $\beta$-Dthiogalactopyranoside and $\mathrm{L}$-arabinose were then added at final concentrations of $0.1 \mathrm{mM}$ and $0.5 \mathrm{mg} / \mathrm{ml}$, respectively, to allow the expression of griC-griD and the chaperon gene on pGro7. At the same time, 3,4-AHBA was also added at a final concentration $1 \mathrm{mM}$ and the culture was further continued at $15^{\circ} \mathrm{C}$ for 24 hours.

\section{Results and Discussion}

\section{GriC and GriD Are Both Required for Reduction of 3,4-AHBA to 3,4-AHBAL}

On the basis of our findings on grixazone biosynthesis $[5,6]$, we assumed that a reductase catalyzing the reduction of 3,4-AHBA to 3,4-AHBAL should be encoded in the grixazone biosynthesis gene cluster. griD was the most probable candidate for the reductase gene, because GriD showed amino acid sequence similarity (about $30 \%$ identity) to some $\mathrm{NAD}(\mathrm{P})$-dependent aldehyde dehydrogenases. The start codon of griD overlapped with the stop codon of griC, suggesting that these two genes were co-transcribed and co-translated. GriC showed sequence similarity to AMP-binding proteins, including the $N$-terminal AMP-binding domain of a CAR of Nocardia sp. $[12,13]$. The Nocardia CAR has a reductase domain in the $C$-terminal portion and catalyzes the reduction of aryl carboxylic acids to the corresponding aldehydes through acyl-AMP formation, followed by NADPH-dependent reduction of the intermediate $[12,13]$. This suggests that the Nocardia CAR is like a GriC-GriD fusion protein. The computer search predicted that GriC and GriD were functionally related, since GriC and GriD homologues are encoded adjacently on the chromosomes of various bacteria, such as SCO7115-SCO7114 in Streptomyces coelicolor A3(2) [14], thnN-thnO in S. cattleya [8], MAP3493-MAP3494 in Mycobacterium avium [15], STH579-STH578 in Symbiobacterium thermophilum [16], ehpF-ehpG in E. herbicola [7], and Plu3307-Plu3306 in Photorhabdus luminescens [17] (the anterior genes encode GriC homologues and the posterior genes encode GriD homologues). We therefore expected that GriC and GriD would constitute a carboxylic acid reductase (Fig. 2).

To reveal the functions of GriC and GriD in the 


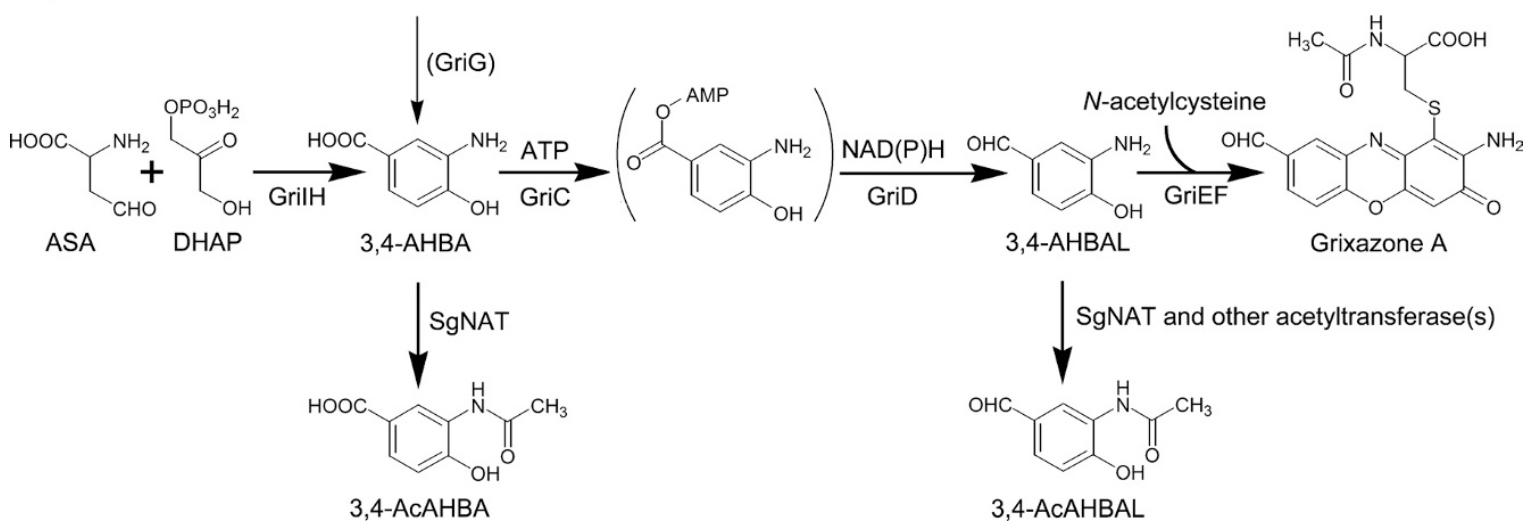

Fig. 2 The proposed biosynthetic pathway leading to grixazone $A$ and shunt products, 3,4-AcAHBA and 3,4-AcAHBAL.

Grixazone $A$ is synthesized through the following three steps: (i) 3,4-AHBA production from two primary metabolites by Gril and GriH [5], (ii) the reduction of 3,4-AHBA to 3,4-AHBAL by GriC-GriD (this study), and (iii) the formation of grixazone $\mathrm{A}$ in the presence of $\mathrm{N}$ acetylcysteine by GriE and GriF [6]. A hypothetical pathway for reduction by GriC and GriD, on the basis of the sequence homology of GriC/GriD with the CAR of Nocardia [12], is also shown. GriG is nonessential for grixazone biosynthesis but apparently contributes the uptake of 3,4-AHBA excreted and/or leaked from the cells (this study). 3,4-AcAHBA is produced from 3,4-AHBA by a cytosolic enzyme, SgNAT, encoded by natA in S. griseus [9]. SgNAT is also responsible for $N$-acetylation of 3,4-AHBAL to produce 3,4-AcAHBAL, but other acetyltransferase(s) must be involved in the $\mathrm{N}$-acetylation (this study). ASA, L-aspartate 4-semialdehyde; and DHAP, dihydroxyacetone phosphate.

grixazone biosynthesis, we constructed griC- and griDdisrupted strains. Mutant $\Delta g r i C$ has an in-frame deletion of the region corresponding to Asp-10 to Gly-350 of GriC. In mutant $\Delta$ griD, the chromosomal griD sequence corresponding to Pro-6 to Ala-454 was replaced by a short linker, resulting in production of only the first five amino acids of GriD (Met-Ser-Thr-Val-Ala), followed by a Leu. As we expected, $\Delta g r i C$ and $\Delta g r i D$ mutants produced no grixazone and accumulated detectable amounts of 3acetylamino-4-hydroxybenzoic acid (3,4-AcAHBA) in the culture broth, when grown in SMM- 0.25 at $26.5^{\circ} \mathrm{C}$ for 5 days (Fig. 3A). SMM-0.25 contained a low concentration $(0.25 \mathrm{mM})$ of $\mathrm{KH}_{2} \mathrm{PO}_{4}$ to allow expression of the grixazone biosynthesis genes, because the gri genes are expressed under phosphate-depleted conditions [4]. Because 3,4AcAHBA is a shunt product derived from 3,4-AHBA by an arylamine $N$-acetyltransferase (SgNAT) encoded by natA in S. griseus [9], these observations implied that both mutants accumulated 3,4-AHBA. Note that both 3,4-AHBA and 3,4-AcAHBA were never detected in the culture broth of the wild-type $S$. griseus cells under grixazone-producing conditions [6]. The defect of grixazone production in mutants $\Delta$ griC and $\Delta$ griD was complemented by introduction of a low-copy number plasmid containing the intact $g r i C$-griD sequence with the $g r i C$ promoter (data not shown).

We next examined bioconversion of 3,4-AHBA to 3,4AHBAL by E. coli BL21 [pGro7] harboring pCold-griCD that contained a co-translational griC-griD sequence under
(A)

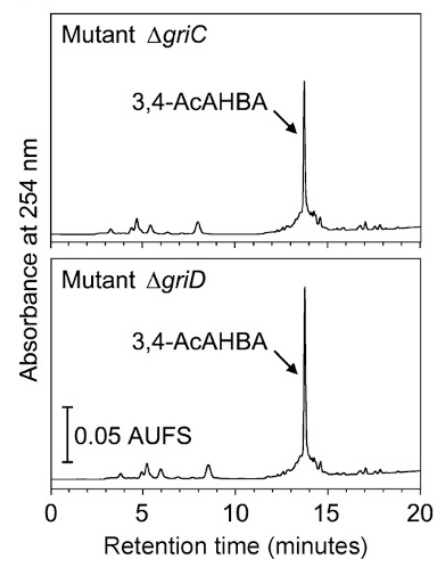

(B)
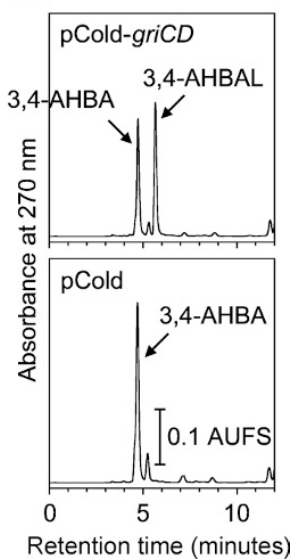

Fig. 3 HPLC analysis of culture broths of $S$. griseus mutants $\triangle$ griC and $\triangle$ griD (A) and E. coli BL21 [pCold-griCD and pGro7] grown in the presence of $1.0 \mathrm{mM} 3,4-\mathrm{AHBA}$ (B).

Authentic samples were used to identify the compounds. (A) Mutants $\triangle$ griC and $\Delta$ griD were cultured at $26.5^{\circ} \mathrm{C}$ for 5 days in SMM- 0.25 and $10 \mu \mathrm{l}$ of the culture broths were analyzed by HPLC. (B) E. coli cells were grown at $15^{\circ} \mathrm{C}$ for 24 hours in LB medium supplemented with $1 \mathrm{mM} 3,4-\mathrm{AHBA}$ and $10 \mu \mathrm{l}$ of the culture broth was analyzed by HPLC. E. coli BL21 [pCold III and pGro7] was used as a negative control. AUFS in (A) and (B), absorbance units full scale.

the control of the cold-shock inducible $\operatorname{csp} A$ promoter on pCold III. When the production of GriC and GriD was initiated, 3,4-AHBA (final concentration, $1 \mathrm{mM}$ ) was added 
to the culture. For 24 hours incubation at $15^{\circ} \mathrm{C}, 3,4$-AHBA added was converted to 3,4-AHBAL with an efficiency of $46 \%$ (Fig. 3B, upper panel). This conversion was not observed in the control strain harboring the empty vector (Fig. 3B, lower panel). These observations suggested that GriC and GriD cooperatively reduced the carboxyl group of 3,4-AHBA to produce 3,4-AHBAL. This enzymatic reaction filled a gap between 3,4-AHBA and 3,4-AHBAL in the grixazone biosynthesis pathway (Fig. 2). The GriCGriD function as a carboxylic acid reductase implies that GriC-GriD homologues, including EhpF-EhpG encoded in the phenazine biosynthesis gene cluster of E. herbicola [7] and ThnN-ThnO encoded in the thienamycin biosynthesis gene cluster of $S$. cattleya [8], are responsible for the reduction of a carboxylic acid to the corresponding aldehyde in the respective biosynthesis, as a novel reductase family.

\section{A Proposed Mechanism of Catalysis by GriC and GriD} GriC shows similarity in amino acid sequence to AMPbinding proteins. GriD shows similarity to NAD(P)dependent aldehyde dehydrogenases. The combination of GriC and GriD appears to constitute a reductase similar to the Nocardia CAR having the $N$-terminal AMP-binding domain and the $C$-terminal reductase domain $[12,13]$. The ATP- and NADPH-dependent reduction of a carboxylic acid to the corresponding aldehyde via an acyl-AMP intermediate has also been found for a long-chain fatty acid reductase complex of luminescence bacteria [18]. On the basis of the knowledge for these enzymes [12, 13, 18], GriC and GriD presumably form a reductase complex and catalyze the reduction as follows: (i) GriC converts 3,4AHBA to an acyl-AMP intermediate, and (ii) GriD reduces the intermediate to 3,4-AHBAL using NAD(P)H (Fig. 2). To clarify the reaction pathway, it is necessary to establish the reductive reaction from 3,4-AHBA to 3,4-AHBAL in vitro by using GriC and GriD proteins. Our repeated attempts to show the reaction in vitro have so far been failed, even by using cell-free extracts of the E. coli BL21 [pCold-griCD and pGro7] and S. griseus $\triangle$ griG [pIJ702griCDG] (see below). This may be ascribed to low stability of GriC and/or GriD.

\section{Possible Roles of griG in Grixazone Biosynthesis}

GriG shows sequence similarity (about 30\% identity) to the aromatic acid $/ \mathrm{H}^{+}$symporter family members [19]. To determine the role of GriG in grixazone biosynthesis, griG on the chromosome of S. griseus was disrupted by inserting the kanamycin/neomycin resistance gene within its coding region. The cells were incubated in SMM- 0.25 for 5 days. In contrast to the observations for mutants $\triangle \mathrm{griC}$ and

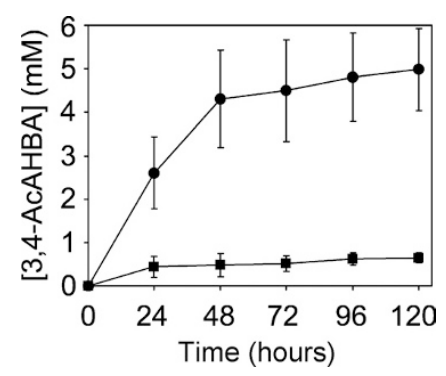

Fig. 4 Bioconversion of 3,4-AHBA to 3,4-AcAHBA by S. griseus cells to estimate the membrane permeability for 3,4-AHBA.

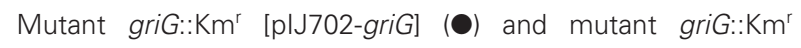
[plJ702-melC1'] (ם) were incubated at $26.5^{\circ} \mathrm{C}$ in SMM-2.5 supplemented with $10 \mathrm{mM} 3,4-\mathrm{AHBA}$. The concentration of 3,4AcAHBA in the culture broth was determined by HPLC. Values are expressed as the mean \pm standard deviation obtained from three independent experiments.

$\Delta g r i D$, mutant $g r i G:: \mathrm{Km}^{\mathrm{r}}$ produced grixazone as the wildtype strain (data not shown), indicating that GriG is not essential for grixazone biosynthesis. However, there is a possibility that GriG have a role in the uptake of 3,4-AHBA excreted and/or leaked from the cells during grixazone biosynthesis, because GriG is a homologue of aromatic acid $/ \mathrm{H}^{+}$symporters. In fact, GriG enhanced apparent membrane permeability of 3,4-AHBA in S. griseus cells as described below.


griG sequence under the control of the melC promoter [11], and a negative control strain, mutant $g r i G:: \mathrm{Km}^{\mathrm{r}}$ [pIJ702melC1'], were cultured for 48 hours in SMM-2.5 (containing $2.5 \mathrm{mM} \mathrm{KH} \mathrm{PO}_{4}$ ) and then 3,4-AHBA (final concentration, $10 \mathrm{mM}$ ) was added to the culture to analyze the bioconversion of 3,4-AHBA to 3,4-AcAHBA. SMM2.5 is more suitable for vigorous growth of $S$. griseus cells than SMM-0.25, but suppresses grixazone biosynthesis

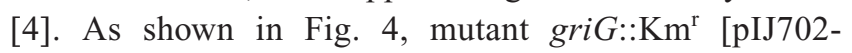
griG] converted 3,4-AHBA to 3,4-AcAHBA much more efficiently than mutant griG:: $\mathrm{Km}^{\mathrm{r}}$ [pIJ702-melC1']. Because 3,4-AcAHBA is produced from 3,4-AHBA by the cytosolic SgNAT [9] and it was very unlikely that GriG increases the enzyme activity of SgNAT, these results

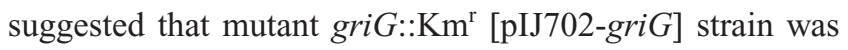
more efficient in the uptake of 3,4-AHBA (and/or the excretion of 3,4-AcAHBA) than mutant $g r i G:: \mathrm{Km}^{\mathrm{r}}$ [pIJ702-melC1'].

\section{Reduction of Some Aryl Carboxylates by Recombinant S. griseus Cells}

We examined the reduction of some aryl carboxylates by $S$. 
griseus [pIJ702-griCDG] containing the three genes, griC, griD and griG, under the control of the melC promoter. Mutant $\triangle$ natA, which is deficient in the ability of $\mathrm{N}$ acetylation of 3,4-AHBA [9], was adopted as the host for the bioconversion. In the bioconversion in which an aryl carboxylic acid was added at a final concentration of $10 \mathrm{mM}$, the most efficient substrate was 3,4-AHBA. 3,4AHBA added was converted to 3,4-AHBAL $(8.0 \pm 0.5 \mathrm{mM}$; data represent the mean \pm standard deviation, obtained from three independent experiments) and 3-acetylamino-4hydroxybenzaldehyde (3,4-AcAHBAL; $1.5 \pm 0.2 \mathrm{mM}$ ). 3,4AcAHBA was not detected. Because 3,4-AcAHBAL was not produced from exogenous 3,4-AcAHBA as described below, it is likely that an acetyltransferase(s) other than SgNAT is responsible for the $N$-acetylation of 3,4-AHBAL. Protocatechuic acid and 4-hydroxybenzoic acid were also converted to protocatechualdehyde $(4.5 \pm 0.2 \mathrm{mM})$ and 4 hydroxy-benzaldehyde $(1.8 \pm 0.4 \mathrm{mM})$, respectively. In addition, this system converted vanillic acid to vanillin $(8.2 \pm 0.3 \mathrm{mM})$, along with the negligible production of vanillyl alcohol $(0.05 \pm 0.01 \mathrm{mM})$, which is probably produced by further reduction of vanillin. All of these aryl carboxylates contain a hydroxy group at the para position of the carboxyl group. 3,4-AcAHBA, 4-amino3-hyddroxybenzoic acid, benzoic acid, salicylic acid, and 5-aminosalicylic acid were hardly reduced. The bioconversion of some aryl carboxylates described above was not observed in the negative control strain harboring pIJ702-griG. It should be mentioned that vanillin, the characteristic aroma component in vanilla, is one of the most important aromatic flavors used widely; a great market demand for natural flavors has brought about a growing interest to produce natural vanillin from natural sources by microbial transformation [20]. This system may have a potential to be employed in production of natural vanillin by microbes, as is suggested for the Nocardia CAR system [13].

Acknowledgments This work was supported by Grant 03A07002 from the Industrial Technology Research Grant Program in 2003 of the New Energy and Industrial Technology Development Organization of Japan and by a Grant-in-Aid for Scientific Research on Priority Areas "Applied Genomics" from Monkasho.

\section{References}

1. Horinouchi S. Mining and polishing of the treasure trove in the bacterial genus Streptomyces. Biosci Biotechnol Biochem 71: 283-299 (2007)

2. Axcel Z, Sabine B-M, Susanne G, Hartmut V, Gerhard S.
Preparation of phenoxazinone derivatives by fermentation with Streptomyces DSM 3813 and their use as parasiticides. European Patent EP260486 (1988)

3. Ohnishi Y, Furusho Y, Higashi T, Chun H-K, Furihata K, Sakuda S, Horinouchi S. Structures of grixazone A and B, A-factor-dependent yellow pigments produced under phosphate depletion by Streptomyces griseus. J Antibiot 57: 218-223 (2004)

4. Higashi T, Iwasaki Y, Ohnishi Y, Horinouchi S. A-factor and phosphate-depletion signals are transmitted to the grixazone biosynthesis genes via the pathway-specific transcriptional activator GriR. J Bacteriol 189: 3515-3524 (2007)

5. Suzuki H, Ohnishi Y, Furusho Y, Sakuda S, Horinouchi S. Novel benzene ring biosynthesis from $\mathrm{C}_{3}$ and $\mathrm{C}_{4}$ primary metabolites by two enzymes. J Biol Chem 281: 36944 36951 (2006)

6. Suzuki H, Furusho Y, Higashi T, Ohnishi Y, Horinouchi S. A novel $o$-aminophenol oxidase responsible for formation of the phenoxazinone chromophore of grixazone. J Biol Chem 281: 824-833 (2006)

7. Giddens SR, Feng Y, Mahanty HK. Characterization of a novel phenazine antibiotic gene cluster in Erwinia herbicola Eh1087. Mol Microbiol 45: 769-783 (2002)

8. Núñez LE, Méndez C, Braña AF, Blanco G, Salas JA. The biosynthetic gene cluster for the $\beta$-lactam carbapenem thienamycin in Streptomyces cattleya. Chem Biol 10: 301-311 (2003)

9. Suzuki H, Ohnishi Y, Horinouchi S. Arylamine $N$ acetyltransferase responsible for acetylation of 2aminophenols in Streptomyces griseus. J Bacteriol 189: 2155-2159 (2007)

10. Hopwood DA, Bibb MJ, Chater KF, Kieser T, Bruton CJ, Kieser HM, Lydiate DJ, Smith CP, Ward JM, Schrempf H. Genetic manipulation of Streptomyces: a laboratory manual. The John Innes Foundation, Norwich, United Kingdom (1985)

11. Katz E, Thompson CJ, Hopwood DA. Cloning and expression of the tyrosinase gene from Streptomyces antibioticus in Streptomyces lividans. J Gen Microbiol 129: 2703-2714 (1983)

12. He A, Li T, Daniels L, Fotheringham I, Rosazza JPN. Nocardia sp. carboxylic acid reductase: cloning, expression, and characterization of a new aldehyde oxidoreductase family. Appl Environ Microbiol 70: 1874-1881 (2004)

13. Venkitasubramanian P, Daniels L, Rosazza JPN. Reduction of carboxylic acids by Nocardia aldehyde oxidoreductase requires a phosphopantetheinylated enzyme. J Biol Chem 282: 478-485 (2007)

14. Bentley SD, Chater KF, Cerdeño-Tárraga A-M, Challis GL, Thomson NR, James KD, Harris DE, Quail MA, Kieser H, Harper D, Bateman A, Brown S, Chandra G, Chen CW, Collins M, Cronin A, Fraser A, Goble A, Hidalgo J, Hornsby T, Howarth S, Huang C-H, Kieser T, Larke L, Murphy L, Oliver K, O’Neil S, Rabbinowitsch E, Rajandream M-A, Rutherford K, Rutter S, Seeger K, Saunders D, Sharp S, 
Squares R, Squares S, Taylor K, Warren T, Wietzorrek A, Woodward J, Barrell BG, Parkhill J, Hopwood DA. Complete genome sequence of the model actinomycete Streptomyces coelicolor A3(2). Nature 417: 141-147 (2002)

15. Li L, Bannantine JP, Zhang Q, Amonsin A, May BJ, Alt D, Banerji N, Kanjilal S, Kapur V. The complete genome sequence of Mycobacterium avium subspecies paratuberculosis. Proc Natl Acad Sci USA 102: 1234412349 (2005)

16. Ueda K, Yamashita A, Ishikawa J, Shimada M, Watsuji T, Morimura K, Ikeda H, Hattori M, Beppu T. Genome sequence of Symbiobacterium thermophilum, an uncultivable bacterium that depends on microbial commensalism. Nucleic Acids Res 32: 4937-4944 (2004)

17. Duchaud E, Rusniok C, Frangeul L, Buchrieser C, Givaudan
A, Taourit S, Bocs S, Boursaux-Eude C, Chandler M, Charles J-F, Dassa E, Derose R, Derzelle S, Freyssinet G, Gaudriault S, Médigue C, Lanois A, Powell K, Siguier P, Vincent R, Wingate V, Zouine M, Glaser P, Boemare N, Danchin A, Kunst F. The genome sequence of the entomopathogenic bacterium Photorhabdus luminescens. Nat Biotechnol 21: 1307-1313 (2003)

18. Meighem EA. Bacterial bioluminescence: organization, regulation, and application of the lux genes. FASEB J 7: 1016-1022 (1993)

19. Pao SS, Paulsen IT, Saier Jr MH. Major facilitator superfamily. Microbiol Mol Biol Rev 62: 1-34 (1998)

20. Priefert H, Rabenhorst J, Steinbüchel A. Biotechnological production of vanillin. Appl Microbiol Biotechnol 56: 296-314 (2001) 